\title{
Value Co-Creation between Public Service Organizations and the Private Sector: An Organizational Capabilities Perspective
}

\author{
Jonathan Rösler*(D), Tobias Söll, Louise Hancock and Thomas Friedli
}

Institute of Technology Management, University of St. Gallen, 9000 St. Gallen, Switzerland; tobias.soell@student.unisg.ch (T.S.); louise.hancock@student.unisg.ch (L.H.); thomas.friedli@unisg.ch (T.F.)

* Correspondence: jonathan.roesler@unisg.ch

check for updates

Citation: Rösler, Jonathan, Tobias Söll, Louise Hancock, and Thomas Friedli. 2021. Value Co-Creation between Public Service Organizations and the Private Sector: An

Organizational Capabilities

Perspective. Administrative Sciences 11: 55. https://doi.org/10.3390/admsci 11020055

Received: 23 April 2021

Accepted: 21 May 2021

Published: 26 May 2021

Publisher's Note: MDPI stays neutral with regard to jurisdictional claims in published maps and institutional affiliations.

Copyright: (c) 2021 by the authors. Licensee MDPI, Basel, Switzerland. This article is an open access article distributed under the terms and conditions of the Creative Commons Attribution (CC BY) license (https:// creativecommons.org/licenses/by/ $4.0 /)$.

\begin{abstract}
Theoretically based on public service logic (PSL), this paper explores the barriers and capabilities surrounding public sector value co-creation with private sector organizations in the context of digital transformation. Specifically, value co-creation efforts at a large public transport and rail infrastructure provider are examined from multiple perspectives using an exploratory case study approach. Based on qualitative interview data, six barriers that hinder value co-creation in public service ecosystems and five corresponding organizational capabilities required to overcome them are identified. The study contributes to the field of public management research by shedding light on the concept of value co-creation in public-private sector digitalization collaborations.
\end{abstract}

Keywords: value co-creation; barriers; organizational capabilities; digital transformation; service innovation; public sector innovation

\section{Introduction}

Cost and budgetary pressures, rising citizen expectations, social and environmental challenges, as well as digital transformation are phenomena driving innovation in the public sector (Andersson and Mattsson 2015; Kaul 1997; Lember 2018; Mulgan and Albury 2003; Pollitt and Hupe 2011; Scott-Kemmis 2009). Governments and public service organizations (PSOs) globally are under pressure to reform administrative structures and processes in order to improve organizational efficiency and public service objectives, such as economic, social welfare, and environmental sustainability outcomes.

Recently, many public administration scholars have declared New Public Management dead and gone (Drechsler 2005; Levy 2010; Lynn 1998), referring to the increasing evidence that the paradigm has failed to deliver on its promise to create a public sector that works better and costs less (Hood and Dixon 2015). Many researchers and practitioners have therefore sought new viable paths for the public sector (Torfing et al. 2016). Inspired by the private sector, in which companies have started the expansion of their service innovation and delivery activities across organizational boundaries, value co-creation is a concept of increasing interest to academics, policymakers, and practitioners in public administration (Vargo et al. 2015; Horne and Shirley 2009; OECD 2011).

In a value co-creation effort, the organization and its customers or service users and other relevant stakeholders engage in "a process of creative problem solving through which relevant and affected actors work across formal institutional boundaries to develop and implement innovative solutions to urgent problems" (Sørensen and Torfing 2018, p. 394). Thus, value co-creation implies the inclusion of various actors to utilize their knowledge, skills, and resources to improve the solution quality and create value that cannot be achieved without cooperation (Agger and Lund 2017; Vargo and Lusch 2016; Vargo et al. 2015). Hence, service providers and users are no longer on opposite sides but interact with each other for the development of new opportunities to create value (Galvagno and Dalli 2014; Moeller et al. 2013). Traditionally inward-looking structures are increasingly shifting 
toward fluid and dynamic partnership-based forms of value co-creation (Jukic et al. 2019; Horne and Shirley 2009; OECD 2011).

In public management research, value co-creation, therefore, refers both to the collaboration of various actors to innovate services to solve a shared problem (Torfing et al. 2016) and to the process by which value is created for service users during and after the service delivery (Hardyman et al. 2019). Despite the substantial potential value co-creation offers for PSOs, particularly in utilizing external resources and competencies to bring digital innovation to the public sector, literature in the area is still in its infancy (Baptista et al. 2020). Given the very specific characteristics of the public sector, many indications suggest that research findings investigating value co-creation in private sector relationships are hardly applicable for the public sector.

Many knowledge gaps in the field, therefore, remain to be addressed through research. For instance, although scholars increasingly acknowledge that resource integration takes place in service ecosystems (Vargo and Akaka 2012; Vargo et al. 2008) involving not only PSOs and citizens but also different types of connected actors that co-create value (Skålén et al. 2015), studies drawing on the notion of the public service ecosystem and public service logic (PSL) are still scarce (Engen et al. 2020). Previous studies have focused predominantly on value co-creation with citizens, while collaboration with private sector organizations remains relatively neglected. In addition, public management literature lacks an understanding of the various barriers and obstacles that hamper value co-creation in practice. In a similar vein, the organizational capabilities and skills required for PSOs value co-creation are scarcely researched. Finally, despite growing interest in the potential of digital technologies to enhance value co-creation in public services, very little is known about their actual impact (Noveck 2015; Kornberger et al. 2017; Lember 2018; Meijer 2012). This is a significant research gap, as many digital services and platforms in public sector organizations are provided and developed jointly with private parties (European Commission 2018; OECD 2016).

Consequently, existing research provides only limited guidance for implementing co-creation in the public sector. Therefore, the purpose of this study is to enhance the understanding of the factors that hinder value co-creation in public service ecosystems and capabilities on the PSOs organizational level that help overcome them. The argumentation is based on the idea that PSL should also focus on co-creation in the triad between citizens, PSOs, and private sector organizations. In the authors' opinions, the boundaries between the public service provider and user are merging in the context of digitalization efforts, such that projects in this area are characterized by the continuous collaboration of users, intermediaries, and stakeholders to innovate, develop, and operate the offering. This study works towards building an ecosystem perspective in public value co-creation by examining the interaction between PSO and private stakeholders. However, the study is limited to the perspective of the PSO, with the two interviews with private stakeholders used for validation purposes only.

To achieve these research aims, the following research questions were developed:

1. What barriers hinder the adoption of value co-creation with the private sector by PSOs?

2. Which organizational capabilities are required by PSOs to overcome these barriers?

To answer these questions, an exploratory case study approach was chosen, drawing on data from interviews held with mid- and senior-level roles within a large state-owned European public transport and rail infrastructure provider. The interview guideline consisted of questions derived from a systematic literature review and focused on numerous public service providers' digital transformation projects, in which the interviewees engaged in during the last couple of years.

Based on this analysis, six barriers hindering value co-creation in public service ecosystems and five corresponding organizational capabilities required to overcome them were identified. The findings suggest that PSOs need to build up distinct organizational capabilities to overcome the various barriers that occur during co-creation efforts involving digital technologies. This study thereby deepens existing understandings of PSO initiated 
co-creation efforts within the context of a complex public service ecosystem. Given the significance placed on digital transformation that was evidenced in the interviews, the findings are of value for public service providers aiming to progress such efforts.

The remainder of the article is organized as follows. Section 2 reviews the literature on value co-creation in the context of public management research and PSL. Section 3 describes the research method upon which this investigation of value co-creation barriers and capabilities is based, and Section 4 presents the study findings and discusses the results in relation to the existing research. Section 5 concludes the paper including implications for theory and practice. Finally, Section 6 identifies limitations and suggests avenues for further research.

\section{Literature Review}

In recent years, public management research has significantly progressed in its understanding of value and the questions of how and by whom value is created during public service production. Although the definition of public value and how it emerges through public service provision and interactions is complex and widely debated (Meynhardt 2009; Osborne and Strokosch 2013; Osborne et al. 2015; Osborne et al. 2016), public management literature increasingly recognizes that value is co-created by the interaction of multiple stakeholders (Vargo and Lusch 2004; Vargo and Lusch 2008; Sicilia et al. 2016). This contrasts with traditional theories and practices emphasizing the internal capacity of organizations to create value, characterized by solitary roles of decision-makers in public administration within a model of closed decision-making in the dyadic interaction process between two entities (Pollitt and Bouckaert 2004).

Although numerous attempts to conceptualize the "magic concept" of co-creation (Pollitt and Hupe 2011) in public service provision have been made (Vargo and Lusch 2004; Vargo and Lusch 2008; Grönroos 2011; Osborne et al. 2016) current research lacks a consistent theoretical definition (Brandsen et al. 2018). Often, two types of collaborative innovations with external stakeholders are distinguished in the literature: Co-production and co-creation (Agger and Lund 2017; Van Dijck et al. 2017; Torfing 2019). Despite the fact that both approaches seem to be related (Vargo and Lusch 2004) or even used interchangeably (Gebauer et al. 2010; Torfing et al. 2016), each concept has its own distinct, albeit linked, theoretical origin (Cluley and Radnor 2019) and characteristics reflective of prevalent thinking around public services at the time where the theories were forming (Dudau et al. 2019).

In addition to questions surrounding terminology and the interpretation of value in the public sector, scholars recently have focused on multi-actor settings in public service systems utilizing PSL (Grönroos and Voima 2013; Osborne et al. 2016; Osborne 2018). PSL focuses on the management of value co-creation to achieve effective public service design and delivery (Hardyman et al. 2015; Osborne et al. 2015; Osborne et al. 2016; Radnor et al. 2014). It also emphasizes that value is created and evaluated by the user throughout the direct interaction with the provider in the value creation process (Grönroos 2008; Grönroos 2011; Grönroos and Voima 2013; Osborne 2018). Despite the relative novelty of PSL, it is not an entirely new theory, rather it is rooted in the service-logic (SL) (Grönroos 2006), service-dominant logic (SDL) (Vargo and Lusch 2004), and public service-dominant logic (PSDL) (Osborne et al. 2013) perspectives that originated in service marketing research. In fact, PSL extends SL and SDL, respectively PSDL by incorporating the ecosystem service lens (Vargo and Lusch 2016; Trischler and Charles 2019; Dudau et al. 2019).

The service ecosystem perspective foregrounds the increasing complexity and dynamics of overlapping, multi-actor service systems in public value co-creation (Skålén et al. 2015; Vargo and Lusch 2016; Rossi and Tuurnas 2019; Dudau et al. 2019) and brings new insights into value co-creation by focusing on the importance of interdependencies, adaptation, and evolution (Beirão et al. 2017; Frow et al. 2014).

Recently, scholars focusing on multi-actor settings in public service systems have researched PSL by utilizing various perspectives and highlighting the necessity of suitable 
organizational structures and sufficient infrastructure (Voorberg et al. 2014), organizational culture (Verschuere et al. 2012; Rossi and Tuurnas 2019), (inter-) organizational dynamics (Tuurnas et al. 2015), social systems (Skålén et al. 2015) or institutionalization (Vargo et al. 2015) in the value co-creation process. Unlike research in the service marketing domain, public management did not widely address the issue of how to add value in the public service domain from an ecosystem perspective (Petrescu 2019). While value co-creation processes in traditional government to citizen $(\mathrm{G} 2 \mathrm{C})$ relationships is well researched, little attention has been paid to PSOs collaborating with private organizations to co-create value.

A significant potential can be derived from such private sector partnerships (e.g., knowledge, skills, and resources), as well as a higher public sector innovation level and improved outcomes for citizens (Commonwealth of Australia 2009; Alves 2013; Agger and Lund 2017). Such successes are evidenced by numerous smart city and energy-efficiency projects co-funded by the European Union as examples of the prominent rise of the smart city paradigm in recent years. The EU has documented the best techniques and role model cases derived from EU-funded energy, mobility, and transport projects implemented, with notable recognition of the importance co-creation processes between government and partners in the context of digital technologies to success (European Commission 2017). However, empirical evidence of co-creation in such ecosystems in the context of digital transformation, as well as the effects of new technologies on co-creation is still scarce (Noveck 2015; Kornberger et al. 2017; Meijer 2012), and importantly, it must be recognized that co-creation does not lead to improvement as an inevitable outcome (Van Dijck et al. 2017). On the contrary, the literature identifies many initiatives of co-creation within the public services context that have failed (Chadwick 2011; Echeverri and Skålén 2011) and documents different barriers to public sector co-creation, although research investigating detailed reasons for failure is scarce. Baptista et al. (2020) categorize structural barriers, which relate to the external environment and limit the predisposition of the actors to engage in co-creation, as well as organizational and behavioral barriers. Different authors have particularly emphasized the specific obstacles that are relevant for PSOs, such as a resistant and risk-averse organizational culture (Tummers et al. 2015; Voorberg et al. 2014), and traditional, inward-looking organizational structures and procedures (Andrews and Brewer 2012; Voorberg et al. 2014), budgetary constraints (European Commission 2019), and the lack of technology or expertise (Lember et al. 2019). Often, the state and governance are reported as impacting co-creation initiatives (Tummers et al. 2015).

Although the literature recognizes that public sector organizations equipped with some capabilities are in a better position to successfully engage in co-creation (Baptista et al. 2020), less research attention has been paid to the actual portfolio of capabilities required to enact PSL logic and overcome the various barriers for adopting co-creation. Capabilities can be defined as the knowledge residing in the routines of an organization to integrate and coordinate its specific resources, skills, and competencies to perform various activities (Zollo and Winter 2002; Helfat and Peteraf 2003).

From the perspectives of the authors, a PSO undertaking value co-creation within PSL must build up a set of organizational capabilities that enable it to co-create value in service exchanges with co-creating partners from both the private or public sector, i.e., citizens, intermediaries, and suppliers. PSL orientation is interpreted as a co-creation capability, resulting from the PSO individuated, relational, and concerted interaction capabilities. Although the merits of capabilities for co-creation are found to be applicable within service marketing literature, the public management environment has not yet studied this topic intensively, although there is some research in the direction of relational capabilities (Klijn et al. 2012; Espino-Rodríguez and Rodríguez-Díazl 2008; Hartmann et al. 2010).

Overall, it is concluded that the existing literature in public management addresses the nature of value co-creation and related concepts but lacks an in-depth understanding of the barriers to adopting co-creation and the corresponding organizational capabilities required to overcome them. The research gap is particularly evident when examining this 
topic from an ecosystem perspective including private sector actors and in the context of digital transformation.

\section{Methodology}

An exploratory case study approach is used to investigate the organizational capabilities required for public-private sector collaborations involving digital transformation, and the barriers and obstacles accompanying this process. The use of a case study serves to extend insights into complex and novel phenomena and is thereby conducive to the extension of existing theories (Eisenhardt and Graebner 2007). Digitization processes, digital technologies, and co-creation in the context of digitalization are novel and insufficiently studied phenomena in scientific research, as discussed earlier in the paper. Hence, this research broadens the view of the topic and supplements theory, thereby justifying the use of an exploratory case study approach.

This paper studies a state-owned European public transport and rail infrastructure provider's engagements in numerous co-creation efforts with business partners in the private sector. An overview of the various organizations involved in the collaborations is shown below in Table 1.

Table 1. Overview of respondents' backgrounds and list of data sources.

\begin{tabular}{ccccc}
\hline Type & Entity & Main Products & Employees & Data Source \\
\hline Public & Alpha & Public Transport & $2000-4000$ & $\mathrm{a}, \mathrm{b}, \mathrm{c}$ \\
Public & Beta & Public Transport & n.a. & $\mathrm{a}, \mathrm{b}, \mathrm{c}$ \\
Public & Gamma & Freight Transport & $>4000$ & $\mathrm{a}, \mathrm{c}$ \\
Public & Delta & Freight Transport & $2000-4000$ & $\mathrm{a}$ \\
Public & Epsilon & Freight Transport & n.a. & $\mathrm{a}, \mathrm{b}, \mathrm{c}$ \\
Public & Zeta & Freight Transport & $>4000$ & $\mathrm{a}, \mathrm{b}$ \\
Public & Eta & Public Transport & $<1000$ & $\mathrm{a}, \mathrm{c}$ \\
Private & Theta & Trains/Signaling & $>40,000$ & $\mathrm{a}, \mathrm{c}$ \\
Private & Iota & Rail Infrastructure & $>4000$ & $\mathrm{a}, \mathrm{c}$ \\
\hline
\end{tabular}

(a) Interviews; (b) internal documents; (c) publicly available resources, i.e., company website, investor reports, and presentations.

The decision to investigate individual collaboration efforts has been made based on the recommendation of Pettigrew (1990), who suggests the use of extreme positions in case studies. The selected methodology considers this recommendation in multiple ways: Firstly, the co-creation efforts were examined from the perspective of both the public transport and the rail infrastructure provider by holding interviews with both parties. Secondly, the inclusion of two interviewees from the private sector, whose organizations have worked with all the PSO interviewees, served as an important confirmation and validation of PSO interviewee responses. Lastly, the co-creation efforts in the sample are sourced from different entities of the rail transport company, with each holding varying interests due to their respective operational performance objectives. This approach and use of the dyadic perspective (Tuli et al. 2007) enable a holistic view of the co-creation effort to be formed.

A semi-structured format was deemed as a suitable approach to interview subject matter experts for the purpose of this study. The approach provides access to knowledge exclusive to the employees interviewed (Liebold and Trinczek 2009) and enables a structured data collection within the conceptual research framework, while also allowing room for complementary points of discussion.

The sample consists of 14 interviews conducted in this manner, in which project managers were questioned about their recently lead digitalization collaborations, as outlined in Table 2. The projects in question were relevant at both the organizational and individual business unit level, as well as to broader European rail operations. The interviewees were selected from the authors' personal networks based on their extensive experience with public-private sector digitalization collaborations across a range of business areas. Conditions for interviewee selection included a minimum of 5 years working with service 
providers and partners in projects concerning digitalization and a maximum of 3 years working at the PSO in an attempt to minimize bias which may arise from long term tenure. Additionally, it was ensured that the sample comprised of interviewees in positions at similar levels of the organizational hierarchy.

Table 2. Overview of respondents, their functions, and case background.

\begin{tabular}{|c|c|c|c|c|}
\hline Type & Entity & Name & Function & Case description \\
\hline Public & Alpha & Rose & Project Leader Digital Platforms & Development and introduction of an \\
\hline Public & Alpha & Kamela & Project Leader Digitalization & IoT-platform \\
\hline Public & Beta & Harry & Head of Digital Platforms & \multirow{3}{*}{$\begin{array}{l}\text { Development of an on-board digital service } \\
\text { offering for passengers }\end{array}$} \\
\hline Public & Beta & Eva & Head of IT-Management & \\
\hline Public & Beta & Emily & Head of Data Management & \\
\hline Public & Gamma & Bill & Head of Vehicle Technology & $\begin{array}{l}\text { Implementation of a condition monitoring } \\
\text { solution for freight containers }\end{array}$ \\
\hline Public & Delta & George & Head of Digital Infrastructure & $\begin{array}{l}\text { Implementation of a predictive } \\
\text { maintenance solution }\end{array}$ \\
\hline Public & Epsilon & John & $\begin{array}{l}\text { Project Leader European } \\
\text { Research Project }\end{array}$ & \multirow{2}{*}{$\begin{array}{l}\text { A public research project on applications of } \\
\text { digital technologies in freight transport } \\
\text { Introduction of a data management and } \\
\text { analytics platform }\end{array}$} \\
\hline Public & Zeta & Kevin & Head of Digital Operations & \\
\hline Public & Eta & Tom & $\begin{array}{l}\text { Project Leader Digital } \\
\text { Operations }\end{array}$ & \multirow{2}{*}{$\begin{array}{l}\text { Implementation of an urban railway } \\
\text { automation system }\end{array}$} \\
\hline Public & Eta & Frank & Project Leader Sales Platform & \\
\hline Private & Theta & Peter & Sales Expert & \multirow{3}{*}{$\begin{array}{l}\text { Introduction of a predictive maintenance } \\
\text { solution } \\
\text { Introduction of asset management software } \\
\text { for rail infrastructure }\end{array}$} \\
\hline Private & Theta & Justin & Head of Partnerships & \\
\hline Private & Iota & Sarah & Head of Digital Infrastructure & \\
\hline
\end{tabular}

Table 2 provides an overview of the interviewees, their functions, and the background of the cases discussed during the interviews. The interviews had a duration of 45 to $85 \mathrm{~min}$ and were conducted by telephone. All interviews were recorded and transcribed, with data analysis facilitated using the software ATLAS.ti.

In addition to the interviews, a document analysis was conducted by analyzing public company reports and websites but partly also internal materials, such as project reports. The triangulation of data sources (Eisenhardt 1989) strengthened the validation of the subjective views of the interviewees, thus increasing the transparency of the collaborative projects studied.

Interview recordings and associated text documents were evaluated via the qualitative content analysis. This method enabled an interpretive approach to data analysis, while at the same time creating a deeper understanding of the individual aspects (Mayring 1991).

The analysis followed a two-step procedure, based on the recommendation of Eisenhardt (1989).

In a first step, individual co-creation efforts were examined separately. The research was conducted using a categorization system, according to which the individual statements of the interviewees were first assigned codes and then transferred into individual categories.

This enabled a detailed understanding of the individual perspectives and discussed facts, as well as an effort-internal identification of underlying patterns.

In a second step, the categories formed for the different efforts were subjected to a closer examination, allowing the connection and identification of patterns between individual co-creation efforts. At the same time, this also revealed differences between the value creation activities of the rail transport company and the other stakeholders. The overarching patterns identified are discussed in the following section. 


\section{Results}

Previous studies in the field of value co-creation have been predominantly concerned with the analysis of dyadic actor relationships, while the existence and proliferation of multiple collaborative relationships in the form of ecosystems associated with digitization have been left out. At the same time, research in the public sector primarily pertains to the involvement of the end customer in the collaboration process, rather than to public sector organizations operating in a stakeholder structure of private sector and government actors.

This study, in contrast, focuses on investigating value co-creation efforts in which different stakeholders operating in a network structure pursue a common value realization. In this setting, the results of this research relate to the barriers and challenges that hinder such collaborations, and to the necessary organizational capabilities that contribute to overcoming them and supporting the co-creation of value.

In the following sections, the results regarding the barriers and capabilities surrounding the public-private sector digitalization co-creation efforts studied are presented. As displayed in Figure 1, barriers are classified as first-order categories and were then aggregated to second-order themes. These themes can be linked with the organizational capabilities identified as necessary to overcome them. In Figure 2, it is emphasized that despite the study's focus on the PSO perspective, the capabilities and barriers are conceptualized such that they are also influenced by the private-sector partner. Sections 4.1 and 4.2 respectively present the barriers and capabilities surrounding the co-creation, with a focus on the PSO perspective, and related findings to the existing literature.

\subsection{Co-Creation Barriers}

In line with prior work, the findings of this study indicate the existence of a range of significant barriers that hamper the co-creation of value within public-private sector collaborations. The six barriers identified relate to the organizational, structural, and behavioral characteristics of the partnership stakeholders, as classified by Baptista et al. (2020), who differentiate between the macro aspects of the external environment, organizational specific factors, and the behaviors of the individuals involved in a co-creation.

The relationship between the characteristics of PSOs and the severity of identified barriers, as well as how the additional complexities surrounding digitalization contribute to these barriers are reported. Findings are summarized in Table 3, along with their relative significance. 


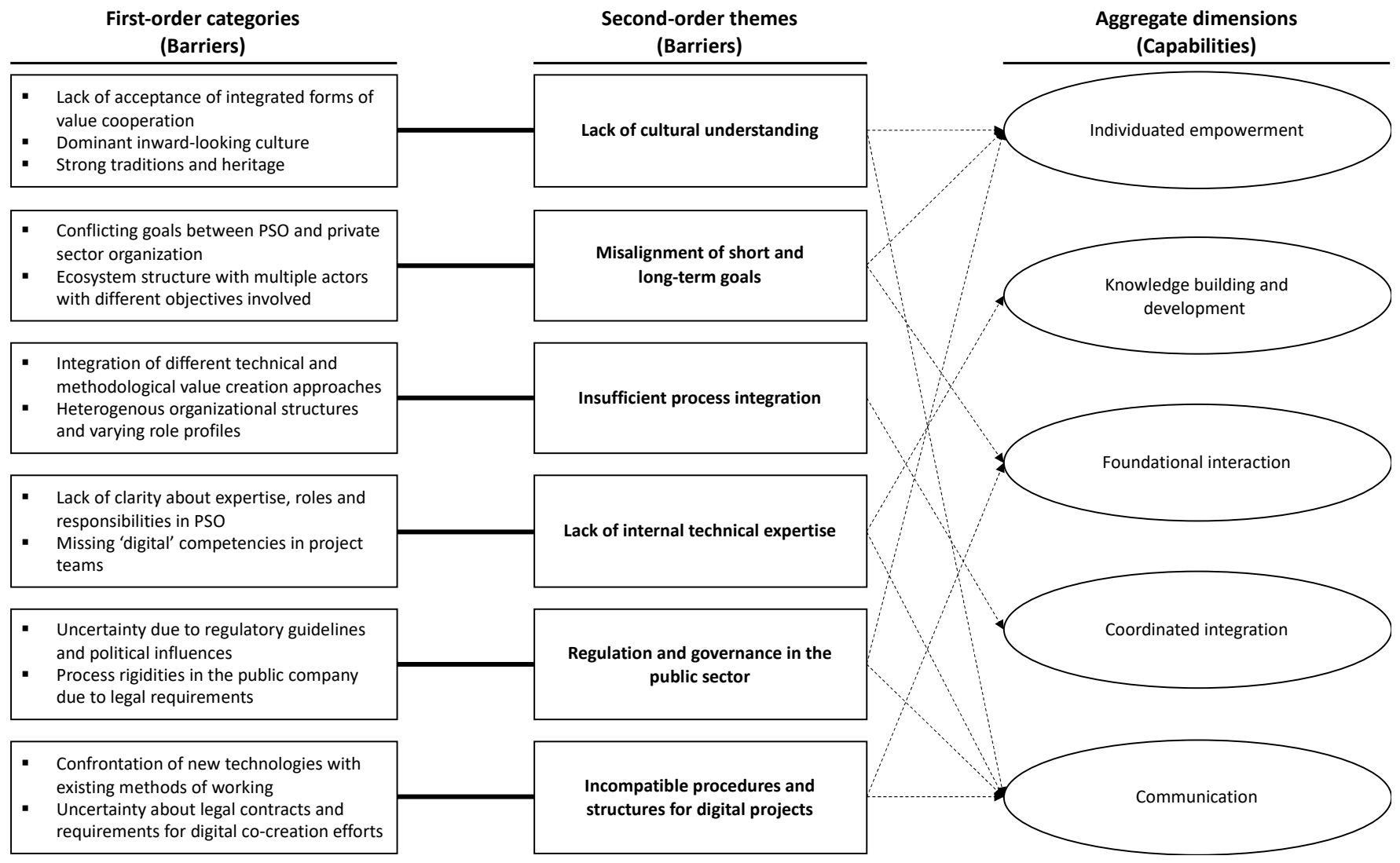

Figure 1. Data structure.

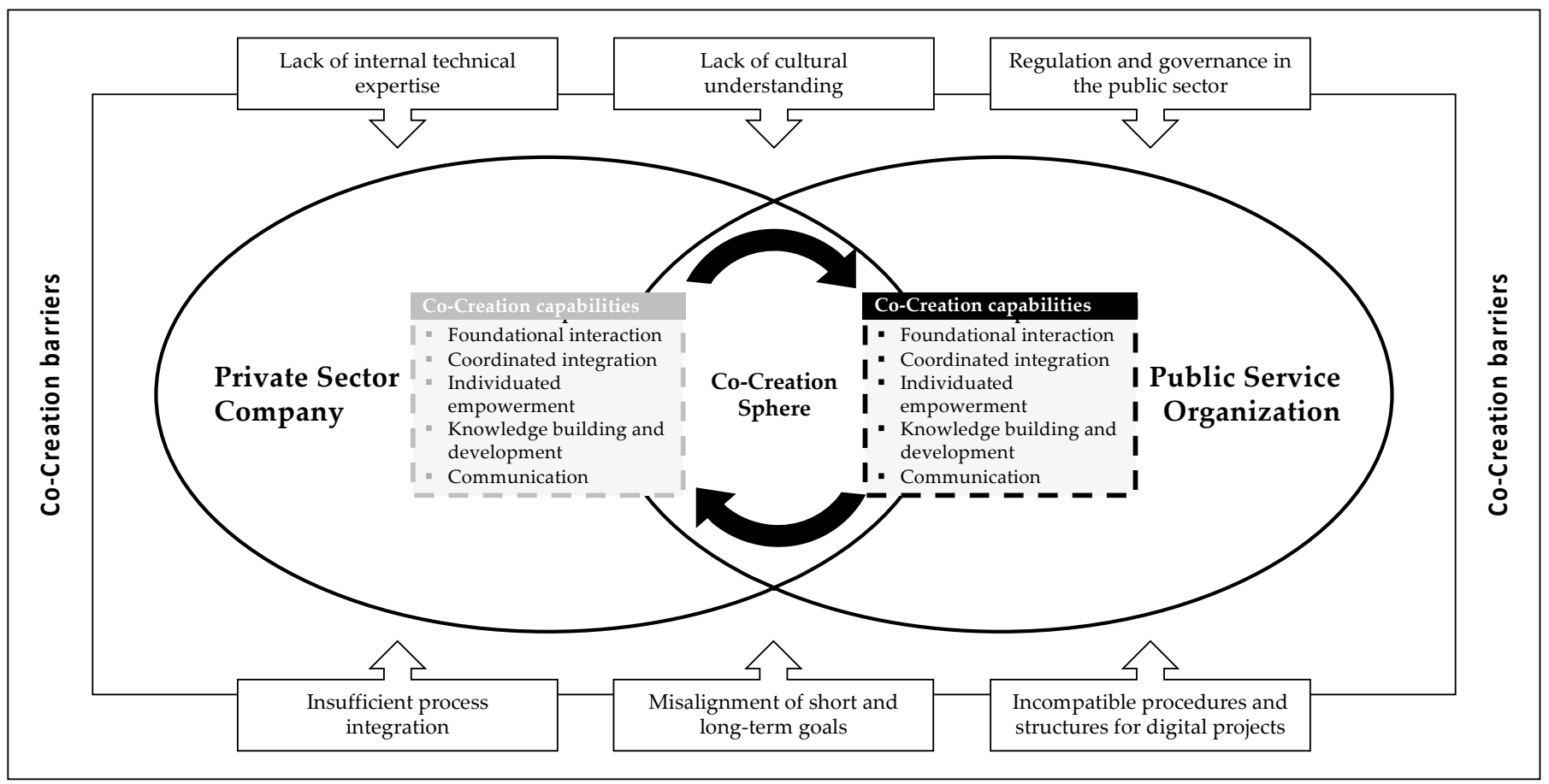

Figure 2. Overview of identified barriers and capabilities for co-creation. 
Table 3. Identified barriers to co-creation.

\begin{tabular}{|c|c|c|c|c|c|c|c|c|c|c|c|c|c|c|}
\hline Barriers & $\begin{array}{l}\ddot{D} \\
\stackrel{0}{\approx}\end{array}$ & 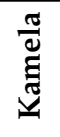 & $\underset{ت}{\mathbb{I}}$ & 空 & 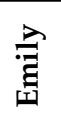 & 浲 & 荀 & 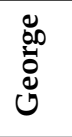 & $\Xi$ & $\underset{\Sigma}{\Xi}$ & ڤ્م & 巳 & $\stackrel{\Xi}{\Xi}$ & $\begin{array}{l}\text { तే } \\
\text { ஸే }\end{array}$ \\
\hline Lack of cultural understanding & + & & & ++ & ++ & + & & + & + & + & + & ++ & ++ & + \\
\hline Misalignment of short and long-term goals & + & + & + & ++ & + & ++ & + & ++ & & + & + & + & ++ & + \\
\hline Insufficient process integration & ++ & ++ & ++ & + & + & & ++ & ++ & + & + & + & - & & ++ \\
\hline Lack of internal technical expertise & ++ & ++ & + & + & ++ & ++ & & + & ++ & ++ & ++ & + & + & \\
\hline Regulation and governance in the public sector & + & + & ++ & + & ++ & ++ & + & & + & + & + & ++ & & - \\
\hline Incompatible procedures and structures for digital projects & + & ++ & + & + & + & ++ & + & ++ & + & + & + & + & ++ & + \\
\hline
\end{tabular}

++ Significant barrier; + basic barrier; - no barrier; empty field = no statement.

\subsubsection{Lack of Cultural Understanding}

The lack of acceptance and understanding of the replacement of a traditional supplierbuyer construct with a more integrated form of value cooperation, both on an individual and organizational level, is viewed as a significant barrier by interviewees: "The more it goes into realization, the more you slip into classic roles where you have to be careful not to lose the spirit of this [... ] cooperation" (Tom, Eta).

A major challenge, therefore, is the transition to joint and integrated value creation, in which the actors view themselves as cooperating partners. In this context, the tradition and heritage of the public service organization hinder the establishment of open organizational culture, a finding supportive of previous literature documenting the inhibiting role of the public-sector organizational culture (Tummers et al. 2015; Voorberg et al. 2014).

In contrast, it should also be noted that a small minority of the sample emphasized the importance of maintaining aspects of a more traditional relationship, in which the PSO maintains control over the service provider: "This steering is an everyday business" (Eva, Beta). "We always have to [... ] influence a bit in which direction [ ... ] [the endeavor] goes, otherwise we can't afford it" (George, Delta).

Nonetheless, the overall findings suggest that both the public sector and private-sector organizations struggle with coordinating the shift, largely viewed as necessary, to more integrated forms of value cooperation within their respective organizations, and jointly: "This hurdle must be overcome [ ... ] jointly because it naturally also means breaking out of this barrier of the customer-supplier construct" (Justin, Theta). Accordingly, the organizations involved are dominated by an inward-looking culture that prevents the initiation of cocreation, and which can only be changed in the long-term: "This is taking much longer than I would ever have expected" (Sarah, Iota).

Consequently, the collaboration stakeholders do not view themselves as a joint team, resulting in negative consequences for collaboration and the outcome of joint value creation cooperation.

\subsubsection{Misalignment of Short and Long-Term Goals}

The establishment of a mutually beneficial collaboration is challenged by the conflicting goals of ecosystem players involved, and in the context of public-private digitalization co-creation efforts, this barrier is particularly acute. The analysis conducted suggests that strongly divergent goals exist on multiple levels of the co-creation effort, in alignment with literature documenting the difficulty in balancing social, organizational, and individual interests (Alves 2013).

Firstly, public-private co-creation efforts face an additional layer of complexity in the joint definition of goals, as objectives to maximize social or political outcomes must be reconciled with those to maximize profit. A second complexity driver is the ecosystem structure of the digitalization co-creation effort, which necessitates the use of numerous specialist and technical competencies. Consequently, a diverse range of players is involved, 
each with individual interests and expectations regarding the co-creation effort. Finally, the long-term nature of digitalization projects enhances the difficulty of determining joint goals: "Of course, in the end, they all have to play together, that is [ ... ] always the challenge" (Harry, Beta). Perspectives gathered from private sector interviewees point to a consensus regarding the difficulty in goal alignment: "I think the biggest challenge in terms of content is to find and create a fair benefit that is of the same nature for both partners" (Justin, Theta). This barrier is a catalyst for conflict between partners regarding the goals and approaches toward the co-creation effort, and the perceived inequitable or unfair distribution of value. The conflict, in turn, diminishes the willingness of stakeholders to participate in the collaboration.

\subsubsection{Insufficient Process Integration}

The insufficient integration of the individual value creation processes of partnership stakeholders is recognized by interviewees as a substantial barrier to value generation. These processes are referred to in co-creation literature as "encounter processes," which involve the exchange of resources such as money, products, work, information, and time and collaborative practices (Payne et al. 2008).

Most prominently in the context of digitalization, issues arise for the PSO at the integration of the different technical and methodological value creation approaches of the collaboration stakeholders: "To unite the different working models in one strategy is a [...] [big] challenge" (Rose, Alpha).

The heterogeneous organizational structures of the public and private sector partners further complicate process integration in public-private collaborations. The hierarchical structure of the public sector differs markedly from the more agile private sector: "There can be conflicting interests [... ] or if they are the same, completely different ways of working and also decision-making powers [ ... ]. You have to reconcile that as well" (Eva, Beta). The consequence of poor process integration is a lack of knowledge transfer between partners, resulting in a lower amount of value generation, and the dissatisfaction of stakeholders involved.

\subsubsection{Lack of Internal Technical Expertise}

The lack of technical expertise in the PSOs is another barrier identified that hinders effective co-creation in the context of digital transformation projects which align with existing literature (Dutu and Diaconu 2017; Magno and Cassia 2014). The data indicate that PSOs are well-advised to build certain digital capabilities internally to manage such projects and external partners efficiently but also stay independent in their decision-making: "Sometimes we just have to believe what [the private sector company] tell us [... ], we don't have the competences to verify this" (John, Epsilon).

In fact, inadequate internal expertise is revealed to be a very important challenge for PSOs engaging in digital transformation projects. However, these data show that PSOs do not per se lack such capabilities, but they often can be found in IT departments that are not represented in such projects. Consequently, the PSOs studied often try to involve such expertise but then face issues to identify and integrate such experts in the project streams:

"In which corner [ ... ] the competence [is available] [ ... ], that can sometimes be found out better on the market than [with the internal service provider]". (Eva, Beta)

Furthermore, an important associated factor that compounds a co-creation barrier is the fact that the studied PSOs also lacked project management skills and experience to effectively manage such large-scale digitalization collaborations. Due to this deficiency, value co-creation can also be hampered by the ensuing communication issues and a lack of understanding, which plagues decision-making. Specifically, a lack of clarity arises around the responsibilities and leadership of stakeholders within the collaboration: "Who is in charge for what? Sometimes we don't know ourselves" (Bill, Gamma). Consequently, PSO teams become reliant on external partners within the collaboration, and the projects are inefficiently coordinated and executed. 


\subsubsection{Regulation and Governance in the Public Sector}

The characteristics of the public-sector organization, including regulatory guidelines, legal requirements, and political influence, serve as barriers to value creation by dictating the processes and speed of the digitalization co-creation effort. These findings are indications of the especially strong role of state and governance traditions in shaping co-creation initiatives (Tummers et al. 2015). Interviewees highlight the relatively large degree of uncertainty that political influence exerts over public sector organizations.

In the context of a co-creation effort, such external decisions and volatility demonstrably impact the collaboration continuity and may alter the defined goals and scopes in a co-creation: "The project is always a bit of a game ball. The reliability of the planning is thus, of course, called into question if effects are permanently coming from outside" (Harry, Beta).

Similarly hampering are process rigidities, such as the time-consuming requirement to tender upon initiation of a partnership, and legal regulations. Regulation concerning the use of digital technologies is particularly troublesome in the context of digitalization, serving to both impede access to external know-how, and prevent rapid adoption of new technology: "As a state-owned company, we have to comply with the EU procurement directives and that means, when we work with external parties, we always have to observe the entire procurement process" (Harry, Beta). Such inefficiencies significantly diminish the value co-creation potential for the public sector in comparison with their private-sector counterparts.

\subsubsection{Incompatible Procedures and Structures for Digital Projects}

As digitization necessitates an adjustment of working methods and new competence development, collaboration stakeholders are required to adapt their organizational structures and processes to facilitate a digitalization co-creation effort. A central element of this stems from the confrontation of new technologies with existing methods of working, which serves as an example of the incompatibility of public-sector organizational structures and procedures with co-creation efforts documented in the literature (Andrews and Brewer 2012; Voorberg et al. 2014): The system [ . . ], which is 150 years old [ . . ], of course, creates a different mindset than when people work at Google, in terms of digitalization" (John, Epsilon).

The interviews indicate that both public and private service organizations are inadequately equipped to handle requirements of co-creation efforts in digitalization (for example, the design of legal contracts and handling of liability cases suitable for digitalization). PSOs are, however, relatively more severely affected, due to a larger deficit of digitalization knowledge, less innovative approaches, and more lengthy decision-making processes: "You invest in the future even though you don't know the benefits yet [ ... ]. I think that already led to the fact that it took a very long time to do the project as well" (Kamela, Alpha).

This culmination of factors leads to the assumption of a subordinate role for the PSO in the collaboration. As a result, implementation processes are prolonged, and decisions have formed the basis of inadequate knowledge.

\subsection{Co-Creation Capabilities}

The second component of the study's findings relates to the PSOs capabilities that support the co-creation of value in a digitalization collaboration with private-sector actors. Based on the analysis, five distinct capabilities that improve the position of PSOs to engage in co-creation efforts are proposed. These capabilities directly connect to the barriers identified in Section 4.1. Given the focus on PSOs, the derived capability set may be viewed as a specific case within the broader context of literature documenting co-creation capabilities.

As depicted in Figure 2, the capabilities identified can be viewed as confronting the six barriers previously discussed. In the following sections, we, therefore, detail the capabilities in unison with the barriers previously reported, thereby establishing clear insights for public-sector digitalization co-creation efforts. 


\subsubsection{Individuated Empowerment}

The ability of organizations to establish an open culture that is receptive to the requirements of integrated value creation is critical to the promotion of joint value realization. As established in the barriers section, the nature of digitalization co-creation tends to conflict with traditional cultural understandings of partnerships, and public sector regulation and governance procedures tend to be incompatible with value co-creation. Thus, it is clear that public sector organizations must foster an organizational culture that is open to change, a finding which is corroborated by private organization interviewees. In relation to the existing literature, this capability can be likened to the importance of building a shared culture and values within customer-supplier relationships (Johnsen 2005; Ngugi et al. 2010), and more directly, with the service-dominant logic derived capability to enable network partners to shape the nature and content of exchange in a collaboration (Karpen et al. 2012). Individuated empowerment necessitates the ability to be receptive to partnership stakeholders instigating the adjustment of existing methods, processes, and structures governing workflows to better align with co-creation goals.

In addition, individuated empowerment encompasses the ability to break down inhibiting silo mentalities and internal orientations of organizations, as further barriers to value co-creation:

"That also means that we consciously leave the paths we have taken so far [...] and [... ] consciously build up new paths, simpler paths, or completely different cooperation models. I think that's actually the most difficult task". (Bill, Gamma)

"The manufacturers also only develop what we demand. If we don't demand anything, they don't develop anything $[\ldots]$. That is, we as [PSO] are responsible [ ... ] for how the development [ ... ] [in] the industry is going". (Tom, Eta)

\subsubsection{Knowledge Building and Development}

The ability of partners to reciprocally develop their skills and knowledge base via formal exchange mechanisms is required for the realization of public-private sector value co-creation. The importance of mutually developing the knowledge and competencies of stakeholder partners was documented in the co-creation capability literature (Karpen et al. 2012; Ngugi et al. 2010), and earlier within broader contexts such as new product and process development (Leonard-Barton 1992).

Reciprocal knowledge development most importantly addresses the barrier of a lack of technical expertise, which affects PSOs acutely in digitalization co-creation efforts. Knowledge sharing mechanisms build partners' knowledge bases and competitiveness individually, thereby countering the barrier of power imbalances in the partnership attributable to knowledge asymmetries: "You have to find models that make it possible for the [... ] [line function] to put that into [operation] quickly and easily" (Rose, Alpha).

More directly, the resulting larger combined knowledge base can be directly leveraged for value generation within the partnership and internally enhances the integration of employees within the organization. In effect, the development of knowledge exchange mechanisms improves the overall quality and ease of collaboration within the partnership:

"In the past it [was] strongly characterized [ . . ] by [the private actors] saying what do you actually want from us [... ]. But it's not like that [anymore]: a-we don't know yet what we want to have and b-that of course [ ... ] [also] helps the respective partners on the other side in the development and evaluation of his components or what he delivers in the future. Because he can [then] improve accordingly and thus [...] of course also with a view to the future, get competitive advantages". (Bill, Gamma)

"The whole topic of data, data exchange, who owns any rights around the data or to the result [ ... ] is, of course, a new [ . . ] and broad field [ . . ], first the knowledge [...] must be [built up] on both sides. So, it's not just lawyers on our side, it's the same with the lawyers on the other side". (John, Epsilon) 


\subsubsection{Foundational Interaction}

The understanding and coordination of the foundational aspects of the co-creation effort is a capability required to overcome the barriers of goal misalignment and the incompatibility of procedures and structures with value co-creation efforts. Reaching a consensus understanding of the co-creation cooperation, and thereby preventing a lapse into a supplier-buyer-natured relationship, is enabled by the close coordination of value network partners to identify the nature of the partnership: "That both agree that we want to build a partnership relationship there, with all parties working toward a goal" (Eva, Beta).

Foundational interaction further refers to acknowledging and addressing the individual goals and requirements of partner stakeholders, including each party's expectations and procedures. The importance of this capability is highlighted by both private and public service partners: "That means we talk openly and honestly about [the] pros and cons and write it down transparently [ ... ]. In this way, we have created a basis of trust that will hopefully carry me through difficult times" (Sarah, Iota).

Lastly, this capability encompasses coordination regarding the recording of required competencies and identification of suitable partners, who provide the resources and means for a co-creation which aligns with public sector goals: "So [based on] a list of criteria or a structured decision [ ... ]. So quite different selection criteria, with whom you then go together." (Eva, Beta). The ability to select appropriate partners who deliver value to the partnership and enable stable management is necessary for value generation, a capability similarly documented in public-sector-specific co-creation literature (Baptista et al. 2020).

The foundational interaction capability further aligns with existing literature which cites the ability to understand partners' resource integration processes, needs, processes, and value sought (Karpen et al. 2012; Terho et al. 2012). Such close coordination on the foundations, in turn, fosters a long-term and trusting relationship between partners, and facilitates partner satisfaction regarding benefit realization:

"Then we fail together, or we just win together. That's also clear to everyone involved".

(Justin, Theta)

\subsubsection{Coordinated Integration}

This study suggests that the coordination and integration of the different performance contributions of partnership stakeholders promote the effective management of co-creation efforts. This finding is in line with the theoretical research of Baptista et al. (2020), who document the importance for public-sector organizations to be able to combine different externally developed resources within a co-creation. From the perspective of servicedominant logic, it can be related to the ability to coordinate and integrate service processes (Karpen et al. 2012), and to develop a strong and effective management structure within a co-creation effort (Ngugi et al. 2010).

Coordinated integration constitutes the ability to control and synchronize the procedural course of the cooperation in a target-oriented manner, with consideration of the contributions and procedures of all partners: "That's how you pack the synergies together [... ] so that each partner here also works into the project, of course to a different extent, but they are all are equally situated [ ... ]" (Emily, Beta). Hence, this capability directly addresses the barrier of process integration in this study. A further component of this capability is to ensure the visibility and appreciation of partners' individual contributions, which is highlighted by the private sector partners: "Along the way, you have to [... ] also closely involve the partners [...] [and] also establish open discussion rounds [ ...], [in which] everyone [...] [contributes] their expertise and then we just develop the use case together." (Peter, Theta). "I brought this task package to the partnership [ ... ]. I know without this task package it would not have been successful. That is, I see both what I delivered in terms of added value and what I [get out] in terms of added value at the end [... ] for myself [... ]. That is the foundation of a long friendship" (Sarah, Iota).

The risk of value drain occurring throughout the collaboration process is, therefore, mitigated by the coordinated integration capability, and the satisfaction of partners 
enhanced. Importantly in the context of digitalization, these abilities are increasingly important to the success of the co-creation as the size of the value network increases.

\subsubsection{Communication}

The ability of partners to communicate effectively throughout the collaboration is highly important with respect to overcoming multiple barriers to value co-creation. This involves the promotion of an ongoing exchange of information and data, including the establishment of appropriate communication points and being able to pass judgment as to whether content should be shared or withheld from partners, with the understanding of the common goal serving as the decisive factor. The capability thus confronts barriers arising from the incompatible procedural and structural characteristics of partners and assists in mitigating the impact of public sector regulation and governance in its establishment of clear communication paths. As a consequence of improved communication quality, there is a larger platform for stakeholders to align on their individual goals, and a basis for the barrier of knowledge asymmetry to be overcome is founded:

"I think that was also one of the decisive success factors, sitting close to each other. So not being far away but creating [ ... ] communication points as much as possible". (Eva, Beta)

"To understand the technicality behind the data [ ... ], to implement it in the processing of the data and then also to provide quality-assured, technically correct data prepared for use cases or for data scientists [... ], that is often very difficult". (Kevin, Zeta)

Specifically relevant for digitalization collaborations, this capability also involves the development of appropriate procedures for the communication and use of intellectual property and data. Thus, the communication capability facilitates an ethical collaboration between network partners. This finding relates to Williams and Aitken (2011), who report a positive relationship between value co-creation and value-based conduct, as well as findings by Karpen et al. (2012) regarding ethical interaction capabilities for the implementation of service-dominant logic. Given the strategic importance of data shared between partners, communication procedures that facilitate ethical interaction are very important in digitalization co-creation:

"So, you have to be very careful to make sure that both sides, when they talk about something [ ... ], [also] mean the same thing and then you have to write it down in a binding way, that's also very important_-bindingness". (Bill, Gamma)

\section{Conclusions}

This study contributes to a deeper understanding of the co-creation efforts of PSOs operating within complex public service ecosystems. A theoretical foundation is found firstly in value co-creation, and secondly in the associated focus on the organizational capabilities that enable the overcoming of barriers and challenges and support the joint generation of value with private companies and other stakeholders. The use of semi-structured interviews in a case study approach enabled us to address the intricacies surrounding co-creation in a public domain in the context of digital transformation. In addition, the distinct physical product structure of the public transport and rail infrastructure sector renders this study a complement to the existing service-oriented research in the area of value co-creation.

It must be highlighted that this study addresses numerous existing research gaps. Firstly, this study responds to calls to build up research on the ecosystem perspective in public management (Petrescu 2019) and observations that studies drawing on the notion of the public service ecosystem and PSL are still scarce (Engen et al. 2020). Additionally, PSL is developed by introducing a capability logic and widening the window towards collaborations with the private sector, thus addressing the call for new theoretical input and perspectives in the field. Lastly, this investigation supports the less researched field of 
digital transformation in public management literature (Noveck 2015; Kornberger et al. 2017; Lember 2018; Meijer 2012).

In summary, this research makes two key contributions. First, the understanding of barriers and obstacles that complicate the initiation and execution of public-private sector value co-creation efforts involving digital technologies is deepened. The findings have particular relevance for collaborations between PSOs and private sector organizations. Second, key capabilities for co-creation in PSOs are explicated.

Addressing the first research question, findings indicate that multiple challenges must be overcome in value co-creation efforts. It is clear that these challenges result on the one hand from the cooperation with the stakeholders themselves, and on the other hand, from internal structures and working methods, which form an obstacle to the introduction of technologies and for cooperation. A substantial challenge arises from the confrontation of traditional forms of work and collaboration models with new digital technologies.

This incites the need to rethink and form a new understanding of the process within PSOs, to tap further potential and to ensure sustainable competitiveness. Government influence plays a significant role in this challenge, as lengthy processes and legal requirements prevent the flexible initiation and implementation of value-generating collaboration with private-sector players or other stakeholders.

Additionally, these findings show that especially when dealing with digital technologies, the existing processes and competencies of PSOs lead to problems that cannot be fully compensated for by co-creation practices. Hence, this study supports previous research findings that PSOs should build new skills in the context of digital transformation and redesign organizational structures, processes, and roles to be more efficient in implementing digital technologies.

In response to the second research question, key capabilities for value co-creation in PSOs based on this data are derived and linked with the corresponding barriers. The data suggest that the collaborative success of co-creation is based heavily on the anchoring of a team and a digitization culture which, together with pronounced communication and fairness, enables the actors involved to work together successfully. As ecosystem structures have an impact on the required capabilities, a more comprehensive way of managing and integrating the performance flows of all stakeholders and partners involved is also of decisive relevance. In such contexts, the data from this study suggest that organizational capabilities for co-creation must be built up by all partners involved and aligned within the collaboration. The respective characteristics of these capabilities are also dependent upon the context in which the co-creation takes place, and the actors involved. Accordingly, overcoming existing barriers and challenges firstly requires a deep understanding of their nature, for the necessary capabilities to be built up and aligned with the involved partners.

This study's detailed investigation of PSO-initiated co-creation efforts supports the need defined in the scientific literature for a more detailed validation and complementation of organizational capabilities for co-creation. The novel analysis of a PSOs co-creation collaboration from different perspectives within the PSO and the perspectives of two private organizations creates a more holistic understanding of these capabilities. Findings complement previous research investigating such capabilities from a PSO-citizen perspective and indicate overlaps with studies on organizational capabilities for co-creation and barriers more broadly, as referenced in the Results section. Notably, strong similarities between the capability set identified in this paper and the Ngugi et al. (2010) study on co-creation capabilities for SMEs and the conceptual model of service dominant orientation by Karpen et al. (2012) in the context of the private sector are prevalent. These findings thereby deepen the existing understanding of co-creation capabilities, and, alongside the analysis of the evident barriers and challenges in the context of digitization, form a platform for future research that further substantiates the influence of network and ecosystem structures in the public sector. 


\section{Research Limitations and Future Research}

As with all research, this study has its inevitable limitations which offer promising directions for future research. Further research could extend the sample by focusing on other PSOs in collaboration with private sector actors, while also including the citizen perspective in the analysis.

For several reasons, the study findings cannot necessarily be generalized to broader contexts. The data stems from a relatively small and purposely developed sample. A larger sample would be necessary to delve into the root of cases where interviewees had conflicting views or to verify the research question answers using statistical analysis. A more heterogenous sample of interviewees, in terms of the organizational level or length of employment, would also create a more diverse and holistic perspective on the case studies examined. Additionally, the study subject, a public transport and rail infrastructure provider, might be not a typical PSO. The findings, therefore, are mainly applicable to larger PSOs with professional structures. Furthermore, while the focus of this study was on identifying a broad set of capabilities for co-creation, one should acknowledge that for many PSOs certain capabilities, such as those for communication and interaction with private sector actors, are of greater importance.

As this study focused on the PSO perspective, more research adopting a multi-actor perspective to explore co-creation efforts with PSOs is needed, particularly from that of the private sector or the citizen. Future research might take a confirmatory approach and operationalize the identified barriers and capabilities, to provide further evidence of the phenomena studied. Additionally, while these findings illustrate that the barriers which were identified are consistent with those of previous studies (Åhlström and Nordin 2006; Toots et al. 2017), interdisciplinarity remains to be addressed in detail by academic literature. The identified cultural challenges of this study are to be emphasized and connected with the common consensus finding. It is apparent that these barriers play a significant role in contexts involving a variety of stakeholders, and therefore a deeper understanding of the partners' respective intentions and goals is required for successful value co-creation.

Moreover, given the specific context of digital transformation, further research could aim to understand how PSOs can overcome technical barriers and build up distinct digital capabilities, as these findings indicate a positive relationship between such capabilities and co-creation outcomes. Furthermore, this research reveals the duality of these barriers, which arise both in the context of the partnership and internally to the participating organization. Therefore, future research clarifying capabilities on the relationship level between the PSO and its partner, and those relating to the PSO and its partner internally would be valuable. The data also indicate that corresponding capabilities for co-creation must not only be built up at the organizational level but also on an individual level. Therefore, further research to investigate the routines and processes underlying the proposed capabilities of this study would be beneficial. Finally, studies aiming to better understand the differences between organizational-level and individual capabilities, such as individual skills and their relation to the outcomes of co-creation efforts in the public sector are encouraged.

Author Contributions: Conceptualization, J.R. and T.F.; methodology, J.R. and T.S.; software, T.S.; validation, J.R., T.S. and T.F.; formal analysis, L.H.; investigation, T.S.; resources, T.F.; data curation, T.S.; writing—original draft preparation, J.R.; writing—review and editing, T.S and L.H.; visualization, T.S.; supervision, J.R.; project administration, J.R. All authors have read and agreed to the published version of the manuscript.

Funding: This research received no external funding.

Institutional Review Board Statement: Not applicable.

Informed Consent Statement: Informed consent was obtained from all subjects involved in the study.

Data Availability Statement: Supporting data is available upon request.

Conflicts of Interest: The authors declare no conflict of interest. 


\section{References}

Agger, Annika, and Dorthe Hedensted Lund. 2017. Collaborative Innovation in the Public Sector-New Perspectives on the Role of Citizens? Scandinavian Journal of Public Administration 21: 17-37.

Åhlström, Pär, and Fredrik Nordin. 2006. Problems of establishing service supply relationships: Evidence from a high-tech manufacturing company. Journal of Purchasing and Supply Management 12: 75-89. [CrossRef]

Alves, Helena. 2013. Co-creation and innovation in public services. Service Industries Journal 33: 671-82. [CrossRef]

Andersson, Per, and Lars-Gunnar Mattsson. 2015. Service innovations enabled by the 'internet of things'. IMP Journal 9: 85-106. [CrossRef]

Andrews, Rhys, and Gene A. Brewer. 2012. Social capital, management and public service performance: Evidence from the United States. Public Management Review 15: 19-42. [CrossRef]

Baptista, Nuno, Helena Alves, and Nelson Matos. 2020. Public Sector Organizations and Cocreation With Citizens: A Literature Review on Benefits, Drivers, and Barriers. Journal of Nonprofit $\mathcal{E}$ Public Sector Marketing 32: 217-41.

Beirão, Gabriela, Lia Patrício, and Raymond Fisk. 2017. Value cocreation in service ecosystems: Investigating health care at the micro, meso, and macro levels. Journal of Service Management 28: 227-49. [CrossRef]

Brandsen, Taco, Trui Steen, and Bram Verschuere. 2018. Co-creation and co-production in Public Services: Urgent Issues in Practice and Research. In Co-Production and Co-Creation: Engaging Citizens in Public Services, 1st ed. Edited by Taco Brandsen, Trui Steen and Bram Verschuere. New York: Routledge, pp. 3-8.

Chadwick, Andrew. 2011. Explaining the Failure of an Online Citizen Engagement Initiative: The Role of Internal Institutional Variables. Journal of Information Technology \& Politics 8: 21-40.

Cluley, Victoria, and Zoe Radnor. 2019. Progressing the Conceptualization of Value Co-creation in Public Service Organizations. Perspectives on Public Management and Governance 3: 211-21. [CrossRef]

Commonwealth of Australia. 2009. Innovation in the Public Sector: Enabling Better Performance, Driving New Directions. Canberra: Australian National Audit Office.

Drechsler, Wolfgang. 2005. The Re-Emergence of "Weberian" Public Administration after the Fall of New Public Management: The Central and Eastern European Perspective. Halduskultuur 6: 94-108.

Dudau, Adina, Russ Glennon, and Bram Verschuere. 2019. Following the yellow brick road? (Dis)enchantment with co-design, coproduction and value co-creation in public services. Public Management Review 21: 1577-94. [CrossRef]

Dutu, Amalia, and Mihaela Diaconu. 2017. Community participation for an open public administration: Empirical measurements and conceptual framework design. Cogent Business \& Management 4: 1-22.

Echeverri, Per, and Per Skålén. 2011. Co-creation and Co-destruction: A practice Theory Based Study of Interactive Value Formation. Marketing Theory 11: 351-73. [CrossRef]

Eisenhardt, Kathleen M. 1989. Building Theories from Case Study Research. Academy of Management Review 14: 532-50. [CrossRef]

Eisenhardt, Kathleen M., and Melissa E. Graebner. 2007. Theory Building from Cases: Opportunities and Challenges. Academy of Management Journal 50: 25-32. [CrossRef]

Engen, Marit, Martin Fransson, Johan Quist, and Per Skålén. 2020. Continuing the development of the public service logic: A study of value co-destruction in public services. Public Management Review 23: 1-20. [CrossRef]

Espino-Rodríguez, Tomás, and Manuel Rodríguez-Díazl. 2008. Effects of internal and relational capabilities on outsourcing: An integrated model. Industrial Management and Data Systems 108: 328-45. [CrossRef]

European Commission. 2017. EU Smart Cities Information System. The Making of a Smart City: Best Practices across Europe. Available online: https:/ / smart-cities-marketplace.ec.europa.eu/insights/publications / making-smart-city-best-practices-acrosseurope (accessed on 11 May 2021).

European Commission. 2018. Final Report of the European Location Interoperability Solutions for e-Government. Digital Platform for Public Services. Available online: https:/ /joinup.ec.europa.eu/collection/elise-european-location-interoperability-solutions-egovernment/document/report-digital-platform-public-services (accessed on 27 February 2021).

European Commission. 2019. Thematic Review Workshop from the European Network of Public Employment. Co-creation of Services. Available online: https:/ / op.europa.eu/en/publication-detail/-/publication/f39599a9-140d-11eb-b57e-01aa75ed7 1a1/language-bg (accessed on 27 February 2021).

Frow, Pennie, Janet McColl-Kennedy, Toni Hilton, Anthony Davidson, Adrian Payne, and Danilo Brozovic. 2014. Value propositions: A service ecosystems perspective. Marketing Theory 23: 1-25. [CrossRef]

Galvagno, Marco, and Daniele Dalli. 2014. Theory of value co-creation: A systematic literature review. Journal of Service Theory and Practice 24: 643-83. [CrossRef]

Gebauer, Heiko, Mikael Johnson, and Bo Enquist. 2010. Value co-creation as a determinant of success in public transport services. A study of the Swiss Federal Railway operator (SBB). Managing Service Quality 20: 511-30. [CrossRef]

Grönroos, Christian, and Päivi Voima. 2013. Critical Service Logic: Making Sense of Value Creation and Co-creation. Journal of the Academy of Marketing Science 4: 133-50. [CrossRef]

Grönroos, Christian. 2006. Adopting a service logic for marketing. Marketing Theory 6: 317-33. [CrossRef]

Grönroos, Christian. 2008. Service Logic Revisited: Who Creates Value? And Who Co-creates? European Business Review 20: 298-314. [CrossRef]

Grönroos, Christian. 2011. Value Co-creation in Service Logic: A Critical Analysis. Marketing Theory 11: 279-301. [CrossRef] 
Hardyman, Wendy, Kate Daunt, and Martin Kitchener. 2015. Value Co-creation Through Patient Engagement in Health Care: A Micro-level Approach and Research Agenda. Public Management Review 17: 90-107. [CrossRef]

Hardyman, Wendy, Martin Kitchener, and Kate L. Daunt. 2019. What matters to me! User conceptions of value in specialist cancer care. Public Management Review 21: 1687-706. [CrossRef]

Hartmann, Andreas, Andrew Davies, and Lars Frederiksen. 2010. Learning to deliver service-enhanced public infrastructure: Balancing contractual and relational capabilities. Construction Management and Economics 28: 1165-75. [CrossRef]

Helfat, Constance, and Margaret Peteraf. 2003. The Dynamic Resource-Based View: Capability Lifecycles. Strategic Management Journal 24: 997-1010. [CrossRef]

Hood, Christopher, and Ruth Dixon. 2015. What We Have to Show for 30 Years of New Public Management: Higher Costs, More Complaints. Governance 28: 265-67. [CrossRef]

Horne, Matthew, and Tom Shirley. 2009. Co-Production in Public Services: A New Partnership with Citizens. London: Prime Minister's Strategy Unit.

Johnsen, Rhona. 2005. Smaller Supplier-Larger Customer Relationships: An Exploration of Asymmetry. Bath: University of Bath.

Jukic, Tina, Primož Pevcin, Jože Benčina, Mitja Dečman, and Sanja Vrbek. 2019. Collaborative Innovation in Public Administration: Theoretical Background and Research Trends of Co-Production and Co-Creation. Administrative Sciences 9: 1-17. [CrossRef]

Karpen, Ingo, Liliana Bove, and Bryan Lukas. 2012. Linking Service-Dominant Logic and Strategic Business Practice A Conceptual Model of a Service-Dominant Orientation. Journal of Service Research 15: 21-38. [CrossRef]

Kaul, Mohan. 1997. The new public administration: Management innovations in government. Public Administration and Development 17: 3-26. [CrossRef]

Klijn, Erik Hans, Arwin van Buuren, and Jurian Edelenbos. 2012. The impact of governance: A normative and empirical discussion. In The Handbook of Governance. Edited by David Levi-Faur. Oxford: Oxford University Press, pp. 294-308.

Kornberger, Martin, Renate E. Meyer, Christof Brandtner, and Markus A. Höllerer. 2017. When Bureaucracy Meets the Crowd: Studying "Open Government" in the Vienna City Administration. Organization Studies 38: 179-200. [CrossRef]

Lember, Veiko, Taco Brandsen, and Piret Tõnurist. 2019. The potential impacts of digital technologies on co-production and co- creation. Public Management Review 21: 1665-86. [CrossRef]

Lember, Veiko. 2018. The Increasing Role of Digital Technologies in Co-Production and Co-Creation. In Co-Production and CoCreation Engaging Citizens in Public Services. Edited by Taco Brandsen, Trui Steen and Bram Verschuere. Routledge: Milton Park and Oxfordshire.

Leonard-Barton, Dorothy. 1992. Core capabilities and core rigidities: A paradox in managing new product development. Strategic Management Journal 13: 111-25. [CrossRef]

Levy, Roger. 2010. New Public Management: End of an Era? Public Policy and Administration 25: 234-40. [CrossRef]

Liebold, Renate, and Rainer Trinczek. 2009. Handbuch Methoden der Organisationsforschung: Quantitative und Qualitative Methoden, 1st ed. Edited by Stefan Kuhl, Petra Strodtholz and Andreas Taffertshofer. Wiesbaden: VS Verlag fur Sozialwissenschaften, Wiesbaden: GWV Fachverlage GmbH, pp. 32-56.

Lynn, Laurence E. 1998. A critical analysis of the new public management. International Public Management Journal 1: 107-23. [CrossRef]

Magno, Francesca, and Fabio Cassia. 2014. Public administrators' engagement in services co-creation: Factors that foster and hinder organisational learning about citizens. Total Quality Management $\mathcal{E}$ Business Excellence 26: 11-12.

Mayring, Philipp. 1991. Qualitative Inhaltsanalyse. In Handbuch qualitative Forschung: Grundlagen, Konzepte, Methoden und Anwendungen, 1st ed. Edited by Uwe Flick, Ernst von Kardorff, Heiner Keupp, Lutz von Rosenstiel and Stephan Wolff. München: Beltz Psychologie-Verlags-Union, pp. 209-13.

Meijer, Albert. 2012. Co-production in an Information Age: Individual and Community Engagement Supported by New Media. Voluntas 23: 1156-72. [CrossRef]

Meynhardt, Timo. 2009. Public Value Inside: What is Public Value Creation? International Journal of Public Administration 32: 192-219. [CrossRef]

Moeller, Sabine, Robert Ciuchita, Dominik Mahr, Gaby Odekerken-Schroder, and Martin Fassnacht. 2013. Uncovering Collaborative Value Creation Patterns and Establishing Corresponding Customer Roles. Journal of Service Research 16: 471-87. [CrossRef]

Mulgan, Geoff, and David Albury. 2003. Innovation in the Public Sector. London: Cabinet Office Strategy Unit.

Ngugi, Isaac, Rhona Johnsen, and Péter Erdélyi. 2010. Relational capabilities for value co-creation and innovation in SMEs. Journal of Small Business and Enterprise Development 17: 260-78. [CrossRef]

Noveck, Beth Simone. 2015. Smart Citizens, Smarter State: The Technologies of Expertise and the Future of Governing. Cambridge: Harvard University Press.

OECD. 2011. Public Governance Reviews. Together for Better Public Services: Partnering with Citizens and Civil Society. Available online: https:/ / www.oecd-ilibrary.org/governance/together-for-better-public-services-partnering-with-citizens-and-civilsociety_9789264118843-en (accessed on 20 February 2021).

OECD. 2016. Directorate for Public Governance. Rebooting Public Service Delivery: How Can Open Government Data Help to Drive Innovation? Available online: https:/ / www.oecd.org/gov/digital-government/rebooting-public-service-delivery.htm (accessed on 19 February 2021).

Osborne, Stephen, and Kirsty Strokosch. 2013. It takes two to tango? Understanding the co-production of public services by integrating the services management and public administration perspectives. British Journal of Management 24: 31-47. [CrossRef] 
Osborne, Stephen, Zoe Radnor, and Greta Nasi. 2013. A New Theory for Public Service Management? toward A (public) ServiceDominant Approach. American Review of Public Administration 43: 135-58. [CrossRef]

Osborne, Stephen, Zoe Radnor, and Kirsty Strokosch. 2016. Co-Production and the Co-Creation of Value in Public Services: A. Suitable Case for Treatment? Public Management Review 18: 639-53. [CrossRef]

Osborne, Stephen, Zoe Radnor, Tony Kinder, and Isabel Martínez. 2015. The SERVICE Framework: A Public-service-dominant Approach to Sustainable Public Services. British Journal of Management 26: 424-38. [CrossRef]

Osborne, Stephen. 2018. From public service-dominant logic to public service logic: Are public service organizations capable of coproduction and value co-creation? Public Management Review 20: 225-31. [CrossRef]

Payne, Adrian F., Kaj Storbacka, and Pennie Frow. 2008. Managing the co-creation of value. Journal of the Academy of Marketing Science 36: 83-96. [CrossRef]

Petrescu, Maria. 2019. From marketing to public value: Towards a theory of public service ecosystems. Public Management Review 21: 1733-52. [CrossRef]

Pettigrew, Andrew M. 1990. Longitudinal Field Research on Change: Theory and Practice. Organization Science 1: 267-92. [CrossRef]

Pollitt, Christopher, and Geert Bouckaert. 2004. Public Management Reform: A Comparative Analysis. Oxford: Oxford University Press.

Pollitt, Christopher, and Peter Hupe. 2011. Talking About Government. Public Management Review 13: 641-58. [CrossRef]

Radnor, Zoe, Stephen Osborne, Tony Kinder, and Jean Mutton. 2014. Operationalizing Co-production in Public Services Delivery: The Contribution of Service Blueprinting. Public Management Review 16: 402-23. [CrossRef]

Rossi, Paula, and Sanna Tuurnas. 2019. Conflicts fostering understanding of value co-creation and service systems transformation. In complex public service systems. Public Management Review 23: 254-75. [CrossRef]

Scott-Kemmis, Don. 2009. Promoting Innovation in the Public Sector: Case Studies. Barton: Management Advisory Committee.

Sicilia, Mariafrancesca, Enrico Guarini, Alessandro Sancino, Martino Andreani, and Renato Ruffini. 2016. Public Services Management and Co-Production in Multi-Level Governance Settings. International Review of Administrative Sciences 82: 8-27. [CrossRef]

Skålén, Per, Kotaiba Abdul Aal, and Bo Edvardsson. 2015. Cocreating the Arab Spring: Understanding Transformation of Service Systems in Contention. Journal of Service Research 18: 250-64. [CrossRef]

Sørensen, Eva, and Jacob Torfing. 2018. Co-initiation of Collaborative Innovation in Urban Spaces. Urban Affairs Review 54: 388-418. [CrossRef]

Terho, Harri, Alexander Haas, Andreas Eggert, and Wolfgang Ulaga. 2012. It's almost like taking the sales out of selling-Towards a conceptualization of value-based selling in business markets. Industrial Marketing Management 41: 174-85. [CrossRef]

Toots, Maarja, Keegan Mcbride, Tarmo Kalvet, Robert Krimmer, and Efthimios Tambouris. 2017. A Framework for Data-Driven Public Service Co-production. Paper presented at the 16th International Conference on Electronic Government (EGOV), St. Petersburg, Russia, September 4-7.

Torfing, Jacob, Eva Sørensen, and Asbjørn Røiseland. 2016. Transforming the Public Sector into an Arena for Co-Creation: Barriers, Drivers, Benefits, and Ways Forward. Paper Presented at the EGPA 2016, Utrecht, The Netherlands, April 24-26.

Torfing, Jacob. 2019. Collaborative innovation in the public sector: The argument. Public Management Review 21: 1-11. [CrossRef]

Trischler, Jakob, and Michael Charles. 2019. The Application of a Service Ecosystems Lens to Public Policy Analysis and Design: Exploring the Frontiers. Journal of Public Policy \& Marketing 38: 19-35.

Tuli, Kapil, Ajay Kohli, and Sundar Bharadwaj. 2007. Rethinking Customer Solutions: From Product Bundles to Relational Processes. Journal of Marketing 71: 1-17. [CrossRef]

Tummers, Lars, William Voorberg, and Victor Bekkers. 2015. Ten Policy Recommendations for co-Creation during Social Innovation. Learning from Innovation in Public Sector Environments (LIPSE) Project. Brussels: EU.

Tuurnas, Sanna, Jari Stenvall, Pasi-Heikki Rannisto, Risto Harisalo, and Kari Hakari. 2015. Coordinating co-production in complex network settings. European Journal of Social Work 18: 1-13. [CrossRef]

Van Dijck, Charlotte, Vidar Stevens, Tom Langbroek, Cécile Riche, Koen Verhoest, Trui Steen, David Aubin, and Stéphane Moyson. 2017. Public Sector Innovation through Collaboration. Explaining Antecedents for Collaborative Innovation. Paper presented at the 21st International Research Society on Public Management Conference, Budapest, Hungary, April 19-21.

Vargo, Stephan L., Heiko Wieland, and Melissa Archpru Akaka. 2015. Institutions in innovation: A service ecosystems perspective. Industrial Marketing Management 44: 63-72. [CrossRef]

Vargo, Stephen, and Melissa Akaka. 2012. Value Cocreation and Service Systems (Re)Formation: A Service Ecosystems View. Service Science 4: 207-17. [CrossRef]

Vargo, Stephen, and Robert Lusch. 2004. Evolving to a new dominant logic for marketing. Journal of Marketing 68: 1-17. [CrossRef]

Vargo, Stephen, and Robert Lusch. 2008. Service-dominant logic: Continuing the evolution. Journal of the Academy of Marketing Science 36: 1-10. [CrossRef]

Vargo, Stephen, and Robert Lusch. 2016. Institutions and axioms: An extension and update of service dominant logic. Journal of the Academy of Marketing Science 44: 5-23. [CrossRef]

Vargo, Stephen, Paul Maglio, and Melissa Akaka. 2008. On Value and Value Co-Creation: A Service Systems and Service Logic Perspective. European Management Journal 26: 145-52. [CrossRef]

Verschuere, Bram, Taco Brandsen, and Victor Pestoff. 2012. Co-Production: The State of the Art in Research and the Future Agenda. Voluntas 23: 1083-101. [CrossRef] 
Voorberg, William, Victor Bekkers, and Lars Tummers. 2014. A Systematic Review of Co-Creation and Co-Production: Embarking on the Social Innovation Journey. Public Management Review 17: 1333-57. [CrossRef]

Williams, John, and Robert Aitken. 2011. The Service-Dominant Logic of Marketing and Marketing Ethics. Journal of Business Ethics 102: 439-54. [CrossRef]

Zollo, Maurizio, and Sidney G. Winter. 2002. Deliberate learning and the evolution of dynamic capabilities. Organization Science 13: 339-51. [CrossRef] 